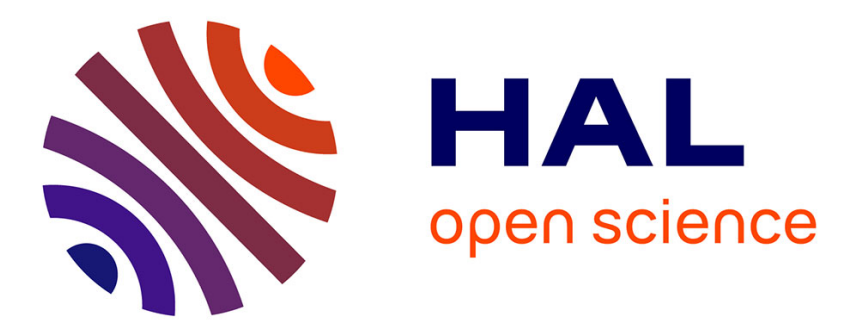

\title{
Probing Variations of Reduction Activity at the Plasma Membrane Using a Targeted Ratiometric FRET Probe
}

Tarushyam Mukherjee, Sriram Kanvah, Andrey S Klymchenko, Mayeul Collot

\section{To cite this version:}

Tarushyam Mukherjee, Sriram Kanvah, Andrey S Klymchenko, Mayeul Collot. Probing Variations of Reduction Activity at the Plasma Membrane Using a Targeted Ratiometric FRET Probe. ACS Applied Materials \& Interfaces, 2021, 13, pp.40315 - 40324. 10.1021/acsami.1c11069 . hal-03424429

\section{HAL Id: hal-03424429 \\ https://hal.science/hal-03424429}

Submitted on 10 Nov 2021

HAL is a multi-disciplinary open access archive for the deposit and dissemination of scientific research documents, whether they are published or not. The documents may come from teaching and research institutions in France or abroad, or from public or private research centers.
L'archive ouverte pluridisciplinaire HAL, est destinée au dépôt et à la diffusion de documents scientifiques de niveau recherche, publiés ou non, émanant des établissements d'enseignement et de recherche français ou étrangers, des laboratoires publics ou privés. 


\title{
Probing Variations of Reduction activity at the Plasma Membrane Using a Targeted Ratiometric FRET Probe
}

\author{
Tarushyam Mukherjee ${ }^{\mathrm{a}}$, Sriram Kanvah ${ }^{\mathrm{a}}$, Andrey S. Klymchenko ${ }^{\mathrm{b} *}$, Mayeul Collot ${ }^{\mathrm{b} *}$ \\ ${ }^{\text {a }}$ Discipline of Chemistry, Indian Institute of Technology Gandhinagar, Palaj, Gandhinagar, Gujarat, India 382355 \\ ${ }^{\mathrm{b}}$ Laboratoire de Bioimagerie et Pathologies, UMR 7021, CNRS/Université de Strasbourg, 74 route du Rhin, 67401 Illkirch- \\ Graffenstaden, France.
}

KEYWORDS. Plasma membrane probe, thiol disulfide exchange, FRET, ratiometric imaging.

\begin{abstract}
The plasma membrane (PM) is the turntable of various reactions that regulate essential functionalities of cells. Among these reactions, the thiol disulfide exchange (TDE) reaction plays an important role in cellular processes. We herein designed a selective probe, called Membrane Reduction Probe (MRP), able to report TDE activity at the PM. MRP is based on a green emitting BODIPY plasma membrane probe connected to a rhodamine through a disulfide bond. MRP is fluorogenic as it is turned off in aqueous media due to aggregation caused quenching (ACQ) and once inserted in PM it displays a bright red signal due to an efficient FRET between the BODIPY donor and the rhodamine acceptor. In PM model, MRP can undergo TDE reaction with external reductive agents as well as with thiolated lipid embedded in the bilayer. Upon TDE reaction the FRET is turned off and a bright green signal appears allowing a ratiometric readout of this reaction. In cells MRP quickly labeled the PM and was able to probe variations of TDE activity using ratiometric imaging. With this tool in hand, we were able to monitor variations of TDE activity at the PM under stress conditions and we showed that cancer cell lines presented a reduced TDE activity at the PM compared to non-cancer cell ones.
\end{abstract}

\section{INTRODUCTION}

The plasma membrane (PM), due to its function of barrier between the extracellular and intracellular environment, plays a crucial role in the regulation of biological phenomena. ${ }^{1}$ The PM is composed of various lipids, forming a bilayer, as well as numerous anchored glycoproteins ensuring its function and the fine control of chemical exchanges. ${ }^{2,}{ }^{3}$ Consequently, a better comprehension of its composition and its chemical environment is of prior importance to decipher biochemical events at the PM and to better understand the involved mechanisms.

Among the regulation mechanisms occurring at the PM, reduction by bio thiols through thiol disulfide exchange (TDE) reaction is implicated in various cellular process, ${ }^{4}$ including PM composition and function, ${ }^{5}$ HIV, hepatitis, and SARSCoV-2 infections, 6, 7, 8 cancer invasion, ${ }^{9,} 10$ and cellular uptake. ${ }^{11,12,13}$ These reactions are not only driven by proteins, ${ }^{14}$ ${ }^{15}$ but also by efflux of glutathione which can be exported across the PM. ${ }^{16,17}$ Consequently, selective probes able to monitor the TDE activity at the level of the PM would lead to a better understanding of this mechanism of regulation in both physiological and stress conditions including pathologies, infections and cancers.

To monitor these reactions with high precision, high space and time resolution, fluorescent probes specifically targeted to the $\mathrm{PM}$ are required. PM probes are valuable tools in bioimaging and found interesting applications in structural studies, ${ }^{18}$ membrane dynamic in live cells, ${ }^{19}$ tracking of exosomes, ${ }^{20}$ and in super-resolution microscopy. ${ }^{21,22,23,23}$
Unlike those probes that accumulate in the membrane to provide a labeling, functional PM probes are able to report on their environment through a change of fluorescence signal. ${ }^{24,25}$ Responsive PM probes were developed to report on lipid order, ${ }^{26,27}$ organization of lipid microdomains, ${ }^{28,29}$ and loss of transmembrane asymmetry during apoptosis. ${ }^{30,} 31$ They were also designed to probe physicochemical parameters of the PM including viscosity, ${ }^{32,}{ }^{33}$ polarity, ${ }^{27}$ membrane tension, ${ }^{34,} 35$ $\mathrm{pH}^{36,37}$ as well as chemical species like metallic cations ${ }^{24}$ or reactive small molecules like reactive oxygen species (ROS) like hypochlorous acid, ${ }^{38}$ or nitric oxide. ${ }^{39,40}$

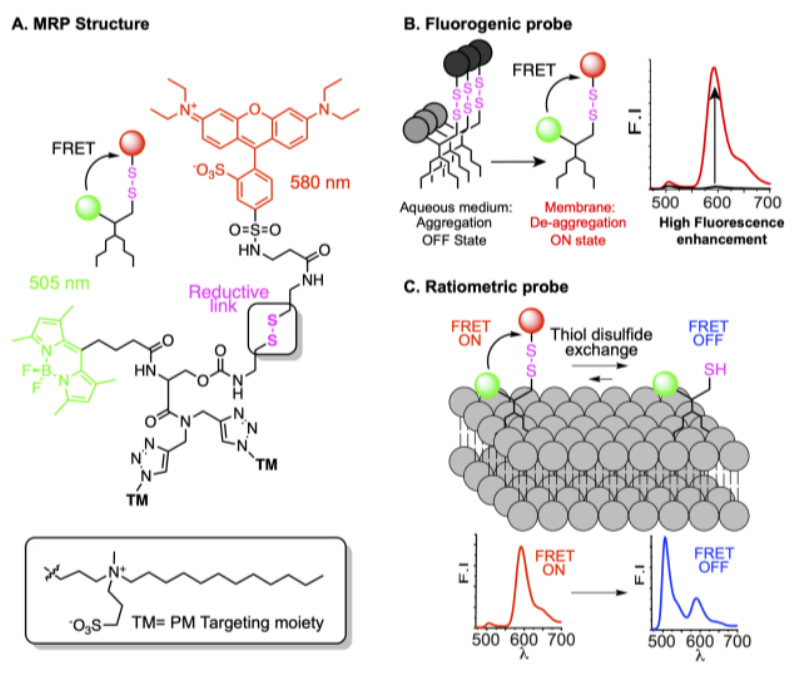


Figure 1. Principle of MRP. MRP is a BODIPY-based membrane probe connected through a disulfide bond to a rhodamine FRET acceptor (A). It is quenched in water due to ACQ and turns on in membrane with a high fluorescence enhancement (B). Once inserted in the PM, MRP undergoes a thiol disulfide exchange reaction that provokes a change of the FRET signal (C).

Despite the numerous fluorescent probes that were developed to sense reductive species based on bio-thiols ($\mathrm{SH}),{ }^{41}$ the literature lacks probes that are specifically targeted at the PM. Although probes for TDE reactions at the cell surface were developed, ${ }^{42,}{ }^{43}$ they only transiently stay at the PM and rapidly cross it to reach the cytoplasm. In part, it is because TDE reactions favor rapid internalization of chemical entities into the cells. ${ }^{11,12,13}$ Moreover, these probes do not display any spectral change upon reaction with surface proteins or thiols. Ratiometric probes can circumvent this drawback, as they provide a ratiometric readout that is neither dependent on their local concentration nor some instrumental settings.

Ratiometric PM probes were developed based on targeted solvatochromic probes ${ }^{27}$ or flippers, ${ }^{34}$ and showed their efficiency in microscopy and nanoscopy applications. ${ }^{29}$ Ratiometric probes can also be obtained by FRET systems that demonstrated their efficiency in cellular imaging to decipher biological phenomenon. ${ }^{44,45,46,47,48}$

Herein we thus intended to develop the first ratiometric TDE probe specifically targeted at the PM. We synthesized MRP (Membrane Reduction Probe, Fig. 1A), a FRET-based ratiometric probe that targets the lipid bilayer of the cell PM regardless of the cell line, state or expression level of their surface proteins. The probe rapidly labels the PM with a high fluorescence enhancement (Fig. 1B) and an efficient FRET efficiency. Its reactivity towards bio-thiols allowed a ratiometric readout of the TDE activity at the PM (Fig. 1C) and revealed significant variation depending on the cellular stress and cell types.

\section{MATERIALS AND METHODS}

Materials. The lipids dioleoylphosphatidylcholine (DOPC), 1,2-dipalmitoyl-sn-glycero-3-phosphothioethanol (DPPTE) were purchased from Avanti polar lipids. TCEP (tris (2carboxyethyl) phosphine), cysteine and NEM (Nethylmalemide) were purchased from Sigma Aldrich.

Synthesis. All starting materials for synthesis were purchased from Alfa Aesar, Sigma-Aldrich or TCI Europe and used as received unless stated otherwise. NMR spectra were recorded on a Bruker Avance III $400 \mathrm{MHz}$ spectrometer. Mass spectra were recorded using an Agilent Q-TOF 6520 mass spectrometer. Protocols for synthesis and characterizations of all new compounds are given in the Supporting Information (SI).

Lipid vesicles. LUVs were obtained by the extrusion method as previously described. ${ }^{49}$ Briefly, a suspension of multilamellar vesicles was extruded by using a Lipex Biomembranes extruder (Vancouver, Canada). The pore size of the filters was first $0.2 \mu \mathrm{m}$ (10 passages) and thereafter $0.1 \mu \mathrm{m}$ (10 passages) to generate monodisperse LUVs with a mean diameter of $0.1 \mu \mathrm{m}$ as measured with a Malvern Zetamaster 300 (Malvern, U.K.). For the experiment with LUVs, the probe (MRP or Membright 488): lipid ratio was set to 1:200. The three different types of thiolated LUVs were prepared by mixing solutions of DOPC (dioleoylphosphatidylcholine) and DPPTE (1,2-dipalmitoylsn-glycero-3-phosphothioethanol) in chloroform at various ratios. ${ }^{50}$ The vesicles were prepared using the same methodology as described above.

Spectroscopy. Absorption and emission spectra were recorded on a Cary 400 Scan ultraviolet-visible spectrophotometer (Varian) and a FluoroMax-4 spectrofluorometer (Horiba Jobin Yvon) equipped with a thermostated cell compartment, respectively. For standard recording of fluorescence spectra, the emission was collected $10 \mathrm{~nm}$ after the excitation wavelength. All the spectra were corrected from a wavelength-dependent response of the detector. For the reduction of the probe, TCEP.HCl (tris (2-carboxyethyl) phosphine hydrochloride), glutathione $(\mathrm{GSH})$ and cysteine were used as reducing agents and the $\mathrm{pH}$ was maintained as 7 (with the help of $0.1 \mathrm{~N}$ $\mathrm{NaOH}$ ) for all the experimental measurements. 100 and 50 $\mathrm{mM}$ of TCEP was used at 100 and $10 \mathrm{mM}$, GSH at $100 \mathrm{mM}$ and $1 \mathrm{mM}$ and cysteine at $50 \mathrm{mM}$ for different experiments from a highly concentrated $2 \mathrm{M}$ stock solution. For all the spectroscopic measurements, MilliQ water (Millipore) and spectroscopic grade solvents were used.

Cytotoxicity. Cytotoxicity of MRP was evaluated by MTT assay (3-(4,5-dimethylthiazol-2-yl)-2,5-diphenyltetrazolium bromide). A total of $5 \times 10^{3} \mathrm{~KB}$ cells/well were seeded in a 96-well plate $18 \mathrm{~h}$ prior to the experiment in Dulbecco's Modified Eagle Medium (Gibco Lifetechnologies - DMEM) complemented with $10 \%$ fetal bovine serum, gentamicin (100 $\mu \mathrm{g} / \mathrm{mL})$, L-glutamine (2 $\mathrm{mM})$, nonessential amino acids (1 $\mathrm{mM})$, and MEM vitamin solution (1\%) and were incubated in a $5 \% \mathrm{CO}_{2}$ incubator at $37{ }^{\circ} \mathrm{C}$. After removal of the medium, an amount of $100 \mu \mathrm{L}$ of MRP solution in DMEM at $200 \mathrm{nM}, 500$ $\mathrm{nM}, 1000 \mathrm{nM}$ was added to the $\mathrm{KB}$ cells and incubated for $2 \mathrm{~h}$ at $37{ }^{\circ} \mathrm{C}\left(5 \% \mathrm{CO}_{2}\right)$. As a control, the cells were incubated with DMEM containing the same percentage of DMSO $(0.5 \% \mathrm{v} / \mathrm{v})$ as the solution of MRP and with triton X100 (0.1\%) as a positive control of cytotoxicity. After $2 \mathrm{~h}$ of dye incubation, the medium was replaced by $100 \mu \mathrm{L}$ of MTT solution in DMEM, and the cells were incubated for $3 \mathrm{~h}$ at $37^{\circ} \mathrm{C}$. Then, $75 \mu \mathrm{L}$ of the solution was replaced by $50 \mu \mathrm{L}$ of DMSO $(100 \%)$ and gently shaken for $15 \mathrm{~min}$ at room temperature. The absorbance at $540 \mathrm{~nm}$ was measured. Each concentration of dye was tested in sextuplicate in 2 independent assays. For each concentration, the percentage of cell viability was calculated in reference to the control DMEM $+0.5 \%$ DMSO without MRP.

Confocal Imaging. KB cells (ATCC CCL-17) were grown in minimum essential medium (MEM, Gibco-Invitrogen) with $10 \%$ fetal bovine serum (FBS, Lonza), $1 \%$ nonessential amino acids (Gibco-Invitrogen), 1\% MEM vitamin solution (GibcoInvitrogen), 1\% L-glutamine (Sigma-Aldrich), and $0.1 \%$ antibiotic solution (gentamicin, Sigma-Aldrich) at $37{ }^{\circ} \mathrm{C}$ in a humidified atmosphere containing $5 \% \mathrm{CO}_{2}$. On the other hand, HeLa, HEK 293 T and 3T3 cells were grown in Dulbecco's modified Eagle medium (DMEM, Gibco-Invitrogen), supplemented with $10 \%$ fetal bovine serum (FBS, Lonza) and $1 \%$ antibiotic solution (penicillin-streptomycin, GibcoInvitrogen) at $37^{\circ} \mathrm{C}$ in humidified atmosphere containing $5 \%$ $\mathrm{CO}_{2}$. For the imaging experiments, cells were seeded onto a 35 $\mathrm{mm}$ IBiDi live cell plates at a density of $1 \times 10^{5}$ cells/well $24 \mathrm{~h}$ before the microscopy measurement. For live cell imaging, the culture medium was removed, and the attached cells were washed with Opti-MEM (Gibco-Invitrogen). The live cells were incubated with MRP for $2 \mathrm{~min}$ at room temperature 
before the medium was washed with Opti-MEM. The fluorescence microscopy was performed on a Leica TSC SPE laser scanning confocal microscope with a $63 \mathrm{X}$ objective. The setting of the channels used were as follows: Donor: excitation laser $488 \mathrm{~nm}$, fluorescence signal: $500-550 \mathrm{~nm}$ (green channel); Acceptor FRET (red) channel: excitation laser $488 \mathrm{~nm}$, fluorescence signal: $570-700 \mathrm{~nm}$.

Oxidative stress. $\mathrm{KB}$ cells were incubated with $2 \mathrm{mM} \mathrm{H}_{2} \mathrm{O}_{2}$ for $1 \mathrm{~h}$ at $37{ }^{\circ} \mathrm{C}$ incubator (supplemented with $5 \% \mathrm{CO}_{2}$ ) to induce oxidative stress. This used concentration of $\mathrm{H}_{2} \mathrm{O}_{2}$ was previously reported to induce the oxidative stress while maintaining the high level of cell viability $(>80 \%)$. $^{51}$ Then, cells were washed with HBSS to remove the trace of $\mathrm{H}_{2} \mathrm{O}_{2}$ from the media and the cells were treated with $200 \mathrm{nM}$ of MRP for 2 min and then the old medium was replaced with fresh OptiMEM before the medium was washed with Opti-MEM. KB cells without $\mathrm{H}_{2} \mathrm{O}_{2}$ treatment were used as a control.

Serum starvation. For observing the changes induced by serum starvation, cells were maintained under nutrient deprived condition (serum depleted media) for 20 hours. Cells were then washed and were treated with $200 \mathrm{nM}$ of MRP for 2 min before the medium was washed with Opti-MEM. KB cells grown in serum supplemented DMEM media were used as a control.

Apoptotic cells. For the apoptosis induction, KB cells were incubated with staurosporine $(1 \mu \mathrm{M})$ for 2 hours at $37{ }^{\circ} \mathrm{C}$ (with $5 \% \mathrm{CO}_{2}$ ) prior to the probe treatment. ${ }^{52}$

NEM (N-ethylmaleimide) administration. $1 \mathrm{mM}$ of $\mathrm{N}$ ethylmaleimide was prepared freshly (from $200 \mathrm{mM}$ stock) in new $1 \mathrm{~mL}$ Opti-MEM media and added into the $35 \mathrm{~mm}$ live cell IBiDi petri dishes replacing the regular growth media. The cells were incubated in this medium for $1 \mathrm{~h}$ at $37^{\circ} \mathrm{C}$ in humidified atmosphere supplemented with $5 \% \mathrm{CO}_{2}$, the media containing NEM was removed and the cells were treated with 200 $\mathrm{nM}$ of MRP for $2 \mathrm{~min}$ before the medium was washed with Opti-MEM. KB cells grown in serum supplemented DMEM media without NEM treatment were used as a control.

Cysteine administration. KB cells and NEM pre-treatment KB cells (1 mM NEM, vide supra) were incubated with cysteine $(50 \mathrm{mM})$ for 1 hour. The medium was then washed with PBS and the cells were treated with $200 \mathrm{nM}$ of MRP for $2 \mathrm{~min}$ before the medium was washed with Opti-MEM.

Image analysis. ImageJ (nih.gov) software was used to process the fluorescence images. The ratiometric images were built using Ratio Intensity Color v3.0, a homemade plugin for imageJ developed by Romain Vauchelles. ${ }^{52}$

\section{RESULTS AND DISCUSSION}

Design of the probe. To ensure a bright and efficient FRETbased probe, BODIPY and sulforhodamine B, a known FRET couple, ${ }^{46}{ }^{53}$ were respectively chosen as FRET donor and acceptor, due to their high molar extinction coefficients, quantum yields and photostability. The FRET pair is connected through a disulfide bond that can be cleaved upon thiol disulfide exchange reaction (TDE) ${ }^{54}$ provoking the separation of the fluorophores and thus the loss of FRET signal (Fig.1). ${ }^{53}$ In order to specifically target the probe to the PM, the BODIPY unit was connected via a serine moiety to two amphiphilic zwitterionic anchors (Fig. 1A) that proved their efficiency and selectivity in our previous works. ${ }^{18,21,22,27,55}$ The nonreductive linkage between the PM targeting moieties and the BODIPY donor allows a strong anchoring at the PM, which ensures that the donor signal remains on the PM even after cleavage, regardless the regioselectivity of the TDE reaction and the nature of the thiol nucleophile: thiolated proteins or glutathion (Fig. S1).

Synthesis. MRP was synthesized via a convergent approach (Scheme 1). First, Sulforhodamine and BODIPY bearing a carboxylic acid for functionalization were prepared (Scheme 1A). Then serine was chosen as a scaffold to bear 1) the BDP donor, 2) the cleavable acceptor and 3) the targeting moieties. For this endeavor, NBoc-Serine was coupled to dipropargylamine to obtain Ser-2 and the hydroxyl group was then transformed into active carbonate to give Ser-3 (Scheme 1B). Next, the cleavable arm that bears the acceptor was synthesized by coupling NBoc-cystamine with Rhod-OH to obtain R-SS-Boc followed by deprotection of the amine leading to $\mathrm{R}-\mathrm{SS}-\mathrm{NH}_{2}$ (Scheme 1C). The different blocs were then assembled: Ser-3 and R-SS-NH $\mathrm{N}_{2}$ were coupled giving rise to R-SS-Ser, which was deprotected before being coupled to BDP-OH to obtain the FRET system R-SS-Ser-BDP (Scheme 1D). The targeting moieties were then installed by click $\mathrm{CuAAC}$ to finally obtain MRP.

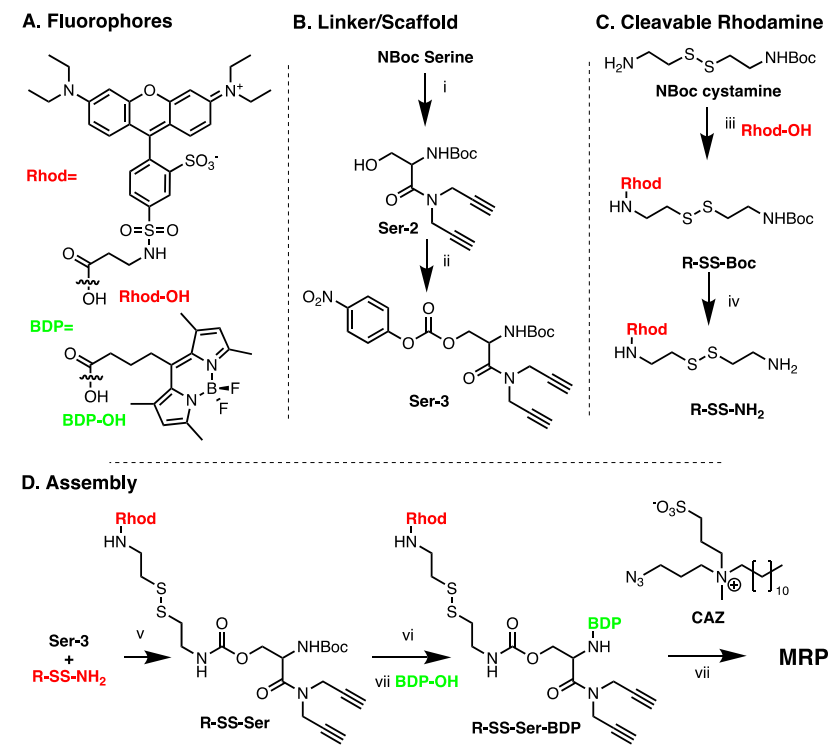

Scheme 1. Synthesis of MRP. Conditions: i. dipropargylamine, HATU, DIEA, DMF. ii. 4-nitrophenyl chloroformate, pyridine, DCM. iii. HATU, DIEA, DMF. iv. TFA, DCM. v. DIE, DCM. vi. TFA, DCM. vii. HATU, DIEA, DMF. viii. $\mathrm{CuSO}_{4} \cdot 5 \mathrm{H}_{2} \mathrm{O}$, sodium ascorbate, DMF, water.

Spectroscopic studies. The photophysical properties of MRP were evaluated in three different solvents namely methanol, DMSO and phosphate buffer (PB). Additionally, $100 \mathrm{~nm}$ size large unilamellar vesicles (LUVs) in phosphate buffer were used as model of PM.

In phosphate buffer, MRP displayed typical signs of aggregation denoted by: 1) hypochromism in absorption compared to absorption spectra in organic solvents (Fig. 2A), 2) higher 
contribution of the shoulders at 460 and $540 \mathrm{~nm}$ due to the formation of $H$-aggregates. ${ }^{21}$ The aggregation was assessed by dynamic light scattering that showed that in water MRP formed small nanoparticles of $27 \pm 1 \mathrm{~nm}$ (Figure S2). Consequently, MRP was virtually non-emissive in water with a low quantum yield of 0.02 due to aggregation caused quenching (ACQ). Conversely, in organic solvent the system displayed high quantum yield up to 0.65 in DMSO. Whereas the maximum absorption and emission wavelengths of the BODIPY donor remained unchanged regardless of the conditions, the rhodamine displayed slight bathochromic shifts of $13 \mathrm{~nm}$ and $17 \mathrm{~nm}$ from methanol to water respectively. In the presence of LUVs, MRP possessed a quantum yield of 0.37 which, makes it a fluorogenic PM probe due to fluorescence enhancement of $>50$-fold from PB to PM model LUVs (Fig. 2B). Moreover, adding MRP to LUVs provoked a fluorescent enhancement which immediately reached a plateau over the time, showing the rapid insertion of the probe in lipid bilayers (Fig. S5).
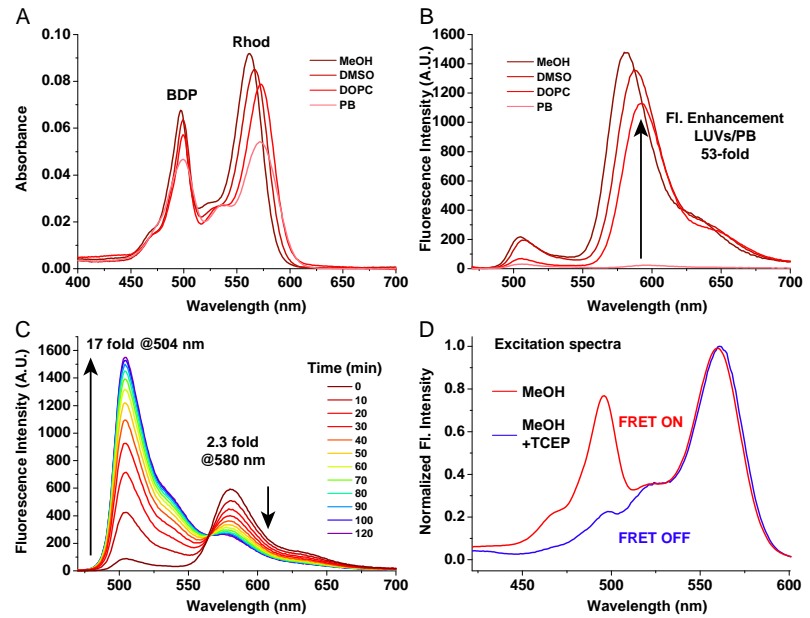

Figure 2. Spectroscopic studies of MRP in solvents. Absorption spectra (A) and emission spectra (B) in various solvents, buffer and DOPC LUVs. Evolution of the emission spectra of MRP in $\mathrm{MeOH}$ and in the presence of $10 \mathrm{mM}$ of TCEP (C). Excitation wavelength was $460 \mathrm{~nm}$. Change of excitation spectra after reduction by TCEP proving the variation of energy transfer (D). Emission was monitored at $610 \mathrm{~nm}$.

Table 1. Photophysical properties of MRP in various conditions

\begin{tabular}{|c|c|c|c|c|}
\hline Conditions & $\begin{array}{c}\lambda_{\mathrm{Abs}} \mathrm{D} / \mathrm{A}^{\mathrm{a}} \\
(\mathbf{n m})\end{array}$ & $\begin{array}{c}\lambda_{\mathrm{Em}} \mathrm{D} / \mathrm{A}^{\mathrm{a}} \\
(\mathbf{n m})\end{array}$ & $\phi$ & $\begin{array}{l}\text { FRET } \\
\text { Eff. }^{\text {b }}\end{array}$ \\
\hline PB & 499 / 573 & $506 / 597$ & 0.02 & 0.43 \\
\hline DMSO & $498 / 567$ & $505 / 587$ & 0.64 & 0.87 \\
\hline LUVs & 499 / 573 & $506 / 593$ & 0.37 & 0.94 \\
\hline МeOH & $495 / 560$ & $505 / 580$ & 0.44 & 0.87 \\
\hline $\begin{array}{c}\text { MeOH+TCEP } \\
\quad(100 \mathrm{mM})\end{array}$ & $496 / 560$ & $505 / 580$ & 0.82 & 0.14 \\
\hline
\end{tabular}

${ }^{\mathrm{a}} \mathrm{D}$ is the FRET Donor: BODIPY, A is the FRET acceptor: Rhodamine.

${ }^{b}$ Relative FRET efficiency measured as $\mathrm{I}_{\mathrm{A}} /\left[\mathrm{I}_{\mathrm{D}}+\mathrm{I}_{\mathrm{A}}\right]$, where $\mathrm{I}$ is the fluorescence intensity.
In emission, the BODIPY showed a much lower contribution compared to the rhodamine denoting the high FRET efficiency, measured as semi-empirical FRET ratio, reaching $87 \%$ in solvents and up to $94 \%$ in LUVs (Table 1). To evaluate both probing properties and the FRET efficiency, MRP was reacted with tris(2-carboxyethyl)phosphine (TCEP) in $\mathrm{MeOH}$ to reduce the disulfide bond and to turn off the FRET. Mass spectrometry analysis of the crude reaction confirmed the response mechanism of MRP to TCPE as the products arising from the disulfide bond cleavage were detected (figure S3). Consequently, upon addition of TCEP both emission and excitation spectra rapidly and dramatically changed (Fig. 2C and D). In emission, the BODIPY donor enhanced by 17-fold whereas the rhodamine signal at $580 \mathrm{~nm}$ was decreased by 2.3 fold. Overall the FRET efficiency changed from $87 \%$ to $14 \%$ and the overall quantum yield increased from 0.44 to 0.82 , which is in line with the quantum yield of MemBright-488 in LUVs, the non-FRET cognate of MRP. ${ }^{18}$ The FRET phenomenon was also confirmed by the excitation spectra of the acceptor (monitored at $680 \mathrm{~nm}$ ) that showed an important contribution of the BODIPY excitation peak at $495 \mathrm{~nm}$ before reduction (Fig. 2D). These results confirmed the high efficiency of the FRET-based probe with a high FRET efficiency value and a high FRET recovery after reduction. The ability of MRP to undergo TDE was also evaluated in the presence of the natural biothiol glutathione and proved to be effective as FRET recovery occurred in a similar manner than with TCEP (Figure S4).

Next, we assessed the ability of MRP to get reduced by diffusive reducing agents while inserted in LUVs' bilayer (Fig. 3A). We first added MRP in DOPC LUVs in the presence of $10 \mathrm{mM}$ TCEP (Fig. 3B). Although the reduction occurred rapidly within $30 \mathrm{~min}$, the FRET recovery was shown to be incomplete compared to reduction in methanol (relative FRET efficiency $26 \%$ and $14 \%$, respectively). This observation probably owns to the fact that the cleaved rhodamine acceptor has a non-negligible affinity towards lipid membrane and thus remains close to the donor. At $100 \mathrm{mM}$ TCEP, the signal monitored at $505 \mathrm{~nm}$ started to decrease after $10 \mathrm{~min}$, probably due to slow reduction of the BODIPY by the strong reductive phosphine TCEP. In milder conditions, using cysteine $(50 \mathrm{mM})$ as thiolated reducing agent to initiate TDE reaction, the reaction was slower. However, MRP successfully probe the TDE reaction mediated by cysteine as the maximum fluorescence intensity at $505 \mathrm{~nm}$ reached with TCEP was reached after $3 \mathrm{~h}$ (Fig. 3C).

Then we wondered if MRP could respond to the presence of reducing moieties at the level of lipid membranes of LUVs, which could model its behavior in cell membranes (Fig. 3D). For this endeavor LUVs composed of DOPC and an increasing proportion of a thiol-bearing lipid DPPTE (from 0 to $50 \%$, Fig. 3D) were prepared. After checking that the different LUVs were identical in size independently of the DPPTE fraction, namely $100 \mathrm{~nm}$ diameter (Fig. 3E), MRP was added with a dye:lipid ratio of 1:200. Upon addition, MRP bound instantaneously to the LUVs regardless their composition, which was evidenced from the burst of the fluorescence intensity (Fig. 3F inset). Once inserted into the lipid membranes, the donor emission of MRP increased steadily for all DPPTE-containing LUVs, suggesting the reduction of the disulfide by the thiolated lipid (Fig. 3F). As expected a higher fraction of DPPTE in LUVs led to faster FRET recovery prov- 
ing that MRP was able to probe the reducing species at li$\mathrm{pid} /$ water interface.

Finally, the photostability of MRP was assessed and was found to be even more stable than our BODIPY PM probe, MemBright-488, composed of the same fluorophore and same PM targeting moieties, thus proving that the pres- ence of a FRET acceptor did not impair the photostability (Fig. S6).

Overall, the spectroscopic data showed that MRP is expected to be an efficient and stable PM probe that is sensitive to both bulk and PM located reductive agents allowing a ratiometric readout of the TDE activity at the cell surface.
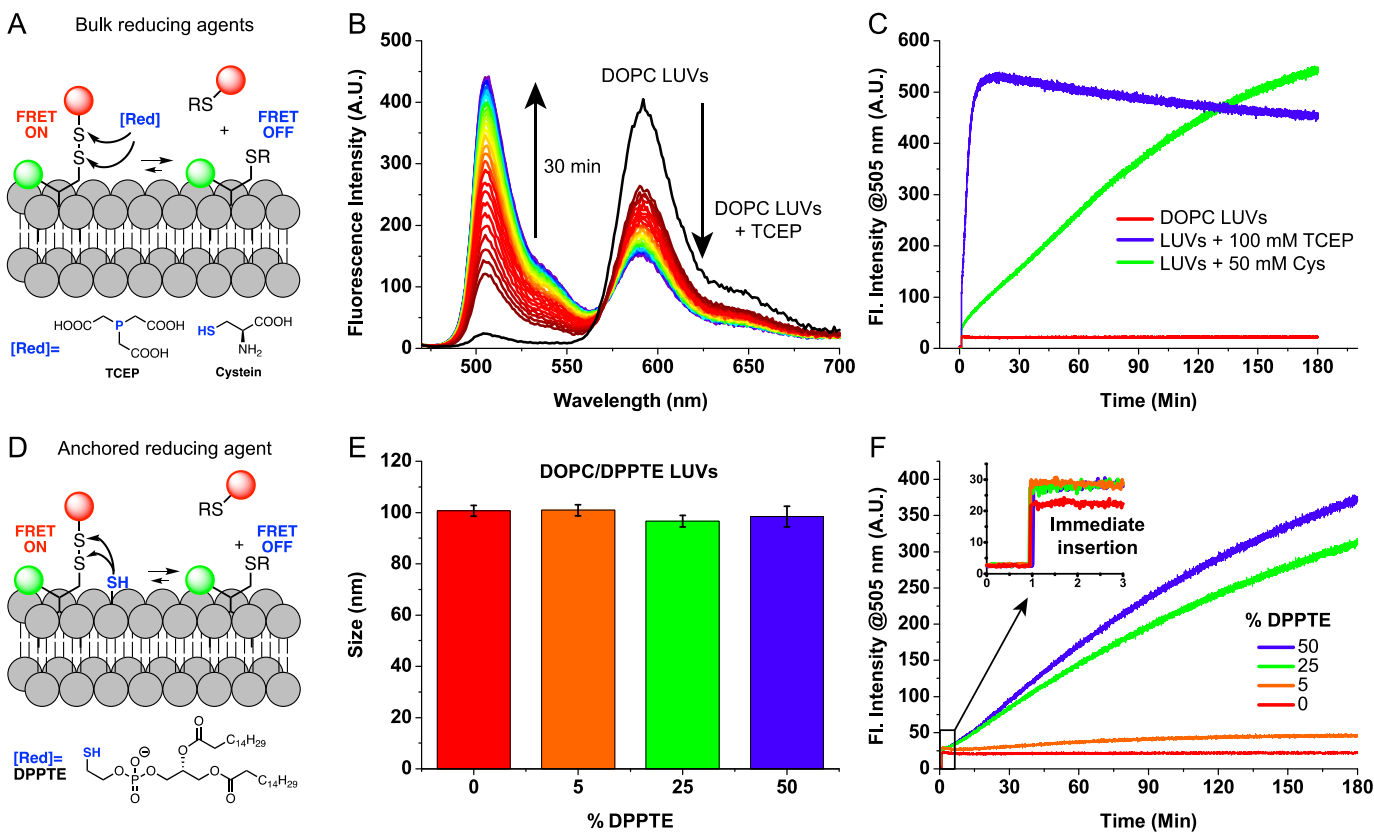

Figure 3. Ratiometric response of MRP to reduction at the PM. Reduction of MRP by bulk reducing agents (A). Fluorescence spectra of MRP in the presence of DOPC LUVs and after addition of TCEP $(10 \mathrm{mM})$ over $30 \mathrm{~min}(\mathrm{~B})$. Monitoring of the donor fluorescence signal at $505 \mathrm{~nm}$ over the time and after addition at $1 \mathrm{~min}$ of TCEP $(100 \mathrm{mM})$ or Cysteine $(50 \mathrm{mM})(\mathrm{C})$. Reduction of MRP by thiolated lipids (D). Size of LUVs with increasing content of thiolated lipid (E). Monitoring of the donor fluorescence signal at $505 \mathrm{~nm}$ over the time and after addition at $1 \mathrm{~min}$ of MRP to the LUVs $(\mathrm{F})$. Inset in F shows the burst increase of fluorescence due to immediate insertion of MRP within the lipid bilayer.

Cellular studies. Before using MRP for cell imaging experiments, its cytotoxicity was assessed by MTT cell viability assay and was proven to be very low even at $1 \mu \mathrm{M}$ concentration (Fig. S7). Then, to evaluate its ability to sense TDE activity at the PM, MRP was first tested on KB cells (Derivatives of HeLa cells). Right after addition of MRP at low concentration (200 nM), the cells' PM displayed a strong emission signal comparable to our previously developed MemBright probes, ${ }^{21}$ with an excellent signal to background ratio, proving the efficiency and selectivity of the probe for PM (Fig. S8). In order to prevent the accumulation of MRP over the time, the cells were washed after 2 min incubation. A green and a red fluorescent channels were used for recording emission from the FRET donor and the acceptor, respectively (Fig. S9). Then, ratiometric images were built by dividing acceptor to donor channels. The rainbow color-code reflected red/green intensity ratio, while intensity corresponded to the sum of intensities of each channel. This ratio is expected to depict the reduction activity at the PM, where red corresponds to a high FRET and thus low TDE activity and the purple color corresponds to a low FRET depicting a high reduction activity.

$\mathrm{PM}$ of normal KB cells stained with MRP displayed rather close green and red fluorescence intensity (Fig. S9) corresponding to an average ratio value of 0.74 (Fig. 4A). Con- versely when cells were pretreated with cysteine the intensity of the green channel increased along with a slight decrease of the red channel (Fig. S9), which is in accordance with our spectroscopic studies. Consequently, the PM displayed a blue pseudo-color (Fig. 4B) with an impressive decrease of average ratio to 0.27 compared to non-treated cells, suggesting that MRP was cleaved and could indeed report TDE activity at the PM.

Then the cells were pretreated with $\mathrm{N}$-methylmaleimide (NEM) that caps the cellular thiol groups by a hetero Michael addition, thus preventing their involvement in TDE reaction. This treatment only led to a slightly higher ratio value of 0.78 (Fig. 4C) suggesting that $\mathrm{KB}$ cells, in normal conditions, do not have an intense TDE activity at the PM. Interestingly, when NEM pretreated KB cells were treated with cysteine, the average ratio had an intermediate value of 0.38 (Fig. 4D), depicting a lower TDE activity than when cells were only treated with cysteine (Fig. 4B). This result shows that MRP is not fully reduced by cysteine itself but probably also by thiolated proteins at the PM that are inactive when treated by NEM.

Once plotted, the ratio histograms obtained from the images clearly showed that upon reducing conditions, the fluorescence signal increased (Fig. 4 E), and the FRET ratio decreased 
significantly (Fig. 4 F), which is in line with our spectroscopic observations in model membranes (Fig 3). Overall, these experiments showed that MRP, combined with the ratiometric imaging, was able to report TDE activity at the PM.

With this tool in hand we intended to see if stress conditions could affect the TDE activity at the PM. For this experiment non-stressed $\mathrm{KB}$ cells were used (Fig. 5A) and were compared to $\mathrm{KB}$ cells that were exposed to different stress conditions: serum depletion, induction of apoptosis and oxidative stress. First, the cells were starved for $20 \mathrm{~h}$ by depletion of serum during the incubation, which was reported to produce changes in different lipid compartments of cells. ${ }^{52}$ The ratiometric images showed no significant change of ratio (Fig. 5D) suggesting that starvation after $20 \mathrm{~h}$ did not led TDE activity at the PM. Then the cells were exposed to staurosporine to provoke late apoptosis. ${ }^{52}$ The obtained ratio of 0.69 (Fig. 5E) suggested that the apoptosis process led to an increase of the TDE activity. Finally, an oxidative stress was induced by means of preincubation with $\mathrm{H}_{2} \mathrm{O}_{2} .{ }^{51}$ In case hydrogen peroxide remained in the cells, its effect on MRP was evaluated in cuvette and showed no interference on the fluorescent signal of MRP (Fig. S10). Although the latter is an oxidative agent, the cells displayed a low ratio comparable with the one obtained in late apoptotic conditions, suggesting that the cells significantly increased their TDE activity to fight against this oxidative stress. Once again, the histograms, with their shift in ratio and increase of intensity, clearly indicated the variation of TDE activity at the PM upon various stress conditions (Fig. 5B).
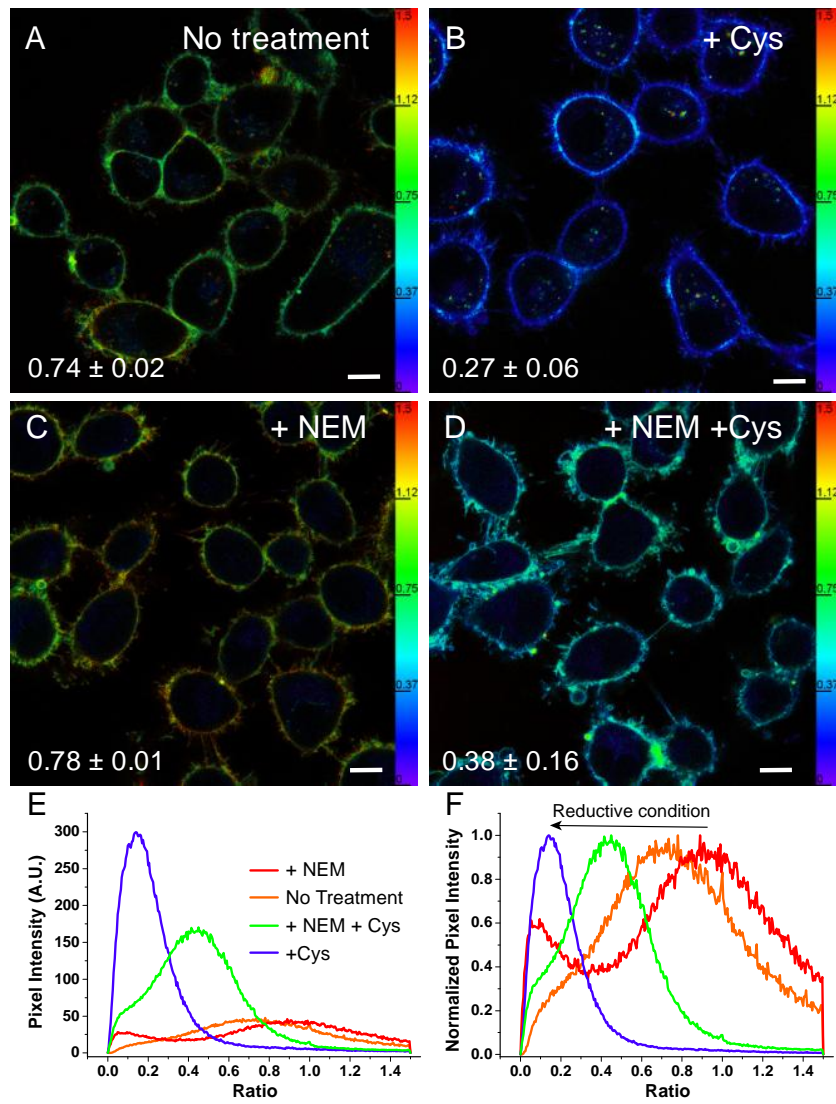

Figure 4. Ratiometric response of MRP at the PM in various conditions. Ratiometric imaging of KB cells stained with MRP in normal conditions (A) and with different stress inducing treatments (B-D). Histograms of the red/green intensity ratio distribu- tion obtained from the ratiometric images (E) and the normalized histograms showing the important shift in ratio $(F)$. Average ratios with standard deviations are indicated at the bottom left of the pictures. Scale bar is $10 \mu \mathrm{m}$.

Finally, we wondered if the TDE activity could differ from different cell lines. We thus tested MRP on another cancer cell line, HeLa (Fig. 5G) and on two non-cancer cell lines, namely 3 T3 (Fig. 5H) and HEK 293T (Fig. 5I). Surprisingly, the images displayed important differences in their average FRET ratio ranging from 0.54 to 0.84 . As a general trend, noncancer cells have a significantly higher TDE activity compared to cancer cells (Fig. 5C). These differences can be assigned to the fact that cancer cells have been shown to have altered extracellular redox activity, ${ }^{10}$ as well as glutathione homeostasis compared to non-cancer cells. ${ }^{56}$ In the case of 3T3 cells, the PM signal appeared more diffused and weaker compared to other cell lines. This difference is assigned to the flat shape of the 3 T3 (fibroblast) cells (see fig. S11). Additionally, intracellular and intense red dots can be observed on the ratiometric images, probably due to quick endocytosis of the rhodamine labeled proteins that were involved in TDE reaction with MRP. This observation deserves a detailed investigation of TDE activity during endocytosis process using MRP.
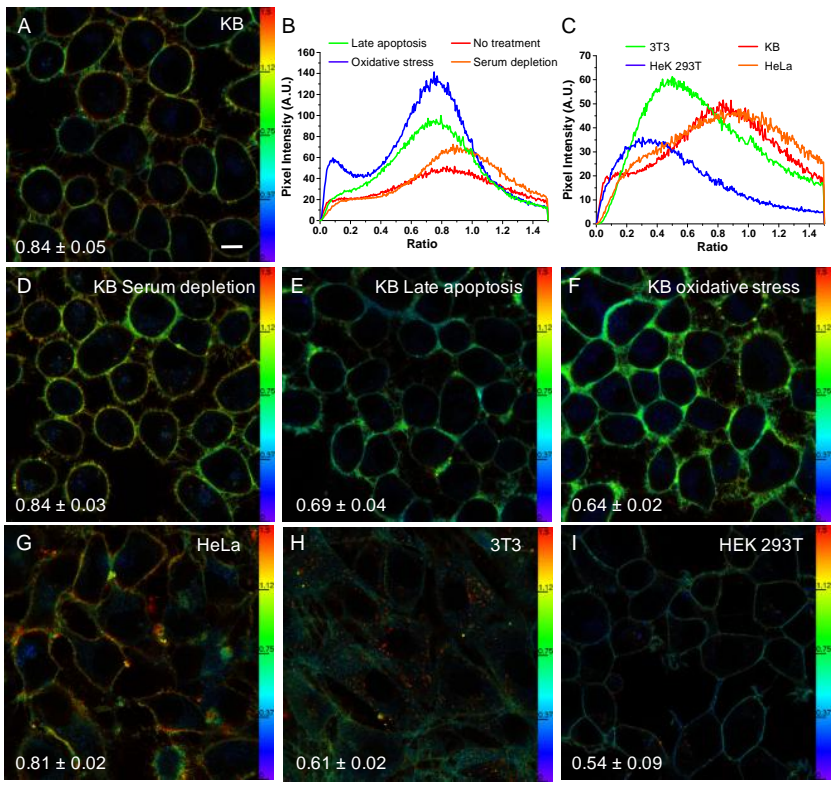

Figure 5. Variation of TDE activity at the PM within stressed cells, and various cell lines. Ratiometric imaging of $\mathrm{KB}$ cells stained with MRP (A). Histograms of the red/green intensity ratio distribution obtained from the ratiometric images for stressed $\mathrm{KB}$ cells (B) and for various cell lines (C). Ratiometric images of KB cells stained with MRP and in different stress conditions (D-F). Ratiometric images of various cell lines stained with MRP (G-I). Average ratios with standard deviations are indicated at the bottom left of the pictures. Scale bar is $10 \mu \mathrm{m}$.

\section{CONCLUSION}

Although numerous fluorescent probes were developed for the detection of biothiols or for thiol disulfide exchange reaction, none of them were specifically targeted to the plasma membrane. $^{24}$ We herein designed, MRP, a PM probes based on BODIPY which is connected to a rhodamine FRET acceptor through a disulfide bond. In both solvents and lipid membrane models MRP displayed a high brightness with high FRET 
efficiency. MRP acted as a fluorogenic probe that was quenched in aqueous media, but de-quenched after rapid insertion into lipid bilayers with a high fluorescence enhancement. Once anchored in the lipid membranes, MRP was able to undergo thiol disulfide exchange reaction driven by bulk reducing agents or embedded thiolated lipid, thus providing a ratiometric readout of the reaction. This ability was verified in cells using ratiometric imaging. MRP was able to report increasing TDE activity at the PM using different controls. As an application, MRP was used to evaluate the differences in TDE activity at the PM of cells in different stress conditions. The results indicated that cells in the conditions of apoptosis or hydrogen peroxide treatment tended to increase their TDE activity at the PM. Finally, MRP reported differences of TDE activity within four cell lines. It appeared that, compared to cancer cells, non-cancer cells had enhanced TDE activity at their surface. Overall MRP proved to be an efficient ratiometric $\mathrm{PM}$ probe to sense reductive activity at the cell surface. However, we are aware that the redox regulation at the PM is complex and MRP cannot distinguish TDE due to surface proteins, glutathione efflux or other redox mechanisms. On the other hand, MRP as a PM probe could be used to monitor TDE activity upon endocytosis process, which will be the topic of a dedicated study.

\section{ASSOCIATED CONTENT}

\section{Supporting Information}

Protocols of synthesis, characterization of new compounds including ${ }^{1} \mathrm{H}$ NMR and ${ }^{13} \mathrm{C}$ NMR and high-resolution mass spectra, and supplementary figures can be found in the supplementary information.

The Supporting Information is available free of charge on the ACS Publications website.

\section{AUTHOR INFORMATION}

\section{Corresponding Author}

* mayeul.collot@unistra.fr, andrey.klymchenko@unistra.fr

\section{Author Contributions}

The manuscript was written through contributions of all authors. I All authors have given approval to the final version of the manuscript. /

\section{ACKNOWLEDGMENT}

This work was supported by the French National Research Agency (ANR) BrightSwitch 19-CE29-0005-01, TM and SK acknowledge IIT Gandhinagar and SERB, Govt. of India (CRG/2018/004020). The authors would like to thank Anil Ashoka for providing DOPC LUVs.

\section{REFERENCES}

(1) Desai, A. J.; Miller, L. J. Changes in the Plasma Membrane in Metabolic Disease: Impact of the Membrane Environment on $G$ Protein-Coupled Receptor Structure and Function. Br. J. Pharmacol. 2018, 175 (21), 4009-4025. https://doi.org/10.1111/bph.13943.

(2) Cooper, G. M. Structure of the Plasma Membrane. Cell Mol. Approach 2nd Ed. 2000.
(3) Lodish, H.; Berk, A.; Zipursky, S. L.; Matsudaira, P.; Baltimore, D.; Darnell, J. Biomembranes: Structural Organization and Basic Functions. Mol. Cell Biol. 4th Ed. 2000.

(4) Yi, M. C.; Khosla, C. Thiol-Disulfide Exchange Reactions in the Mammalian Extracellular Environment. Annu. Rev. Chem. Biomol. Eng. 2016, 7 (1), 197-222. https://doi.org/10.1146/annurevchembioeng-080615-033553.

(5) Ilani, T.; Alon, A.; Grossman, I.; Horowitz, B.; Kartvelishvily, E.; Cohen, S. R.; Fass, D. A Secreted Disulfide Catalyst Controls Extracellular Matrix Composition and Function. Science 2013, 341 (6141), 74-76. https://doi.org/10.1126/science.1238279.

(6) Matthias, L. J.; Yam, P. T. W.; Jiang, X.-M.; Vandegraaff, N.; Li, P.; Poumbourios, P.; Donoghue, N.; Hogg, P. J. Disulfide Exchange in Domain 2 of CD4 Is Required for Entry of HIV-1. Nat. Immunol. 2002, 3 (8), 727-732. https://doi.org/10.1038/ni815.

(7) Fraser, J.; Boo, I.; Poumbourios, P.; Drummer, H. E. Hepatitis C Virus (HCV) Envelope Glycoproteins E1 and E2 Contain Reduced Cysteine Residues Essential for Virus Entry*. J. Biol. Chem. 2011, $286 \quad$ (37), 31984-31992. https://doi.org/10.1074/jbc.M111.269605.

(8) Cheng, Y.; Pham, A.-T.; Kato, T.; Lim, B.; Moreau, D.; López-Andarias, J.; Zong, L.; Sakai, N.; Matile, S. Inhibitors of Thiol-Mediated Uptake. Chem. Sci. 2021, 12 (2), 626-631. https://doi.org/10.1039/D0SC05447J.

(9) Kaiser, B. K.; Yim, D.; Chow, I.-T.; Gonzalez, S.; Dai, Z; Mann, H. H.; Strong, R. K.; Groh, V.; Spies, T. DisulphideIsomerase-Enabled Shedding of Tumour-Associated NKG2D Ligands. Nature 2007, 447 (7143), 482-486. https://doi.org/10.1038/nature05768.

(10) Chaiswing, L.; Zhong, W.; Cullen, J. J.; Oberley, L. W.; Oberley, T. D. Extracellular Redox State Regulates Features Associated with Prostate Cancer Cell Invasion. Cancer Res. 2008, 68 (14), 5820-5826. https://doi.org/10.1158/0008-5472.CAN-08-0162.

(11) Gasparini, G.; Bang, E.-K.; Montenegro, J.; Matile, S. Cellular Uptake: Lessons from Supramolecular Organic Chemistry. Chem. Commun. 2015, 51 (52), 10389-10402. https://doi.org/10.1039/C5CC03472H.

(12) Torres, A. G.; Gait, M. J. Exploiting Cell Surface Thiols to Enhance Cellular Uptake. Trends Biotechnol. 2012, 30 (4), 185-190. https://doi.org/10.1016/j.tibtech.2011.12.002.

(13) Gasparini, G.; Bang, E.-K.; Molinard, G.; Tulumello, D. V.; Ward, S.; Kelley, S. O.; Roux, A.; Sakai, N.; Matile, S. Cellular Uptake of Substrate-Initiated Cell-Penetrating Poly(Disulfide)s. J. Am. Chem. Soc. 2014, $136 \quad$ (16), 6069-6074. https://doi.org/10.1021/ja501581b.

(14) Jiang, X.-M.; Fitzgerald, M.; Grant, C. M.; Hogg, P. J. Redox Control of Exofacial Protein Thiols/Disulfides by Protein Disulfide Isomerase*. J. Biol. Chem. 1999, 274 (4), 2416-2423. https://doi.org/10.1074/jbc.274.4.2416.

(15) Donoghue, N.; Yam, P. T. W.; Jiang, X.-M.; Hogg, P. J. Presence of Closely Spaced Protein Thiols on the Surface of Mammalian Cells. Protein Sci. 2000, 9 (12), 2436-2445. https://doi.org/10.1110/ps.9.12.2436.

(16) Bachhawat, A. K.; Thakur, A.; Kaur, J.; Zulkifli, M. Glutathione Transporters. Biochim. Biophys. Acta BBA - Gen. Subj. 2013, 1830 (5), 3154-3164. https://doi.org/10.1016/j.bbagen.2012.11.018. 
(17) Ballatori, N.; Krance, S. M.; Marchan, R.; Hammond, C. L. Plasma Membrane Glutathione Transporters and Their Roles in Cell Physiology and Pathophysiology. Mol. Aspects Med. 2009, 30 (1), 13-28. https://doi.org/10.1016/j.mam.2008.08.004.

(18) Collot, M.; Boutant, E.; Lehmann, M.; Klymchenko, A. S. BODIPY with Tuned Amphiphilicity as a Fluorogenic Plasma Membrane Probe. Bioconjug. Chem. 2019, 30 (1), 192-199. https://doi.org/10.1021/acs.bioconjchem.8b00828.

(19) Wang, H.; Feng, Z.; Del Signore, S. J.; Rodal, A. A.; Xu, B. Active Probes for Imaging Membrane Dynamics of Live Cells with High Spatial and Temporal Resolution over Extended Time Scales and Areas. J. Am. Chem. Soc. 2018, 140 (10), 3505-3509. https://doi.org/10.1021/jacs.7b13307.

(20) Hyenne, V.; Ghoroghi, S.; Collot, M.; Bons, J.; Follain, G.; Harlepp, S.; Mary, B.; Bauer, J.; Mercier, L.; Busnelli, I.; Lefebvre, O.; Fekonja, N.; Garcia-Leon, M. J.; Machado, P.; Delalande, F.; López, A. A.; Silva, S. G.; Verweij, F. J.; van Niel, G.; Djouad, F.; Peinado, H.; Carapito, C.; Klymchenko, A. S.; Goetz, J. G. Studying the Fate of Tumor Extracellular Vesicles at High Spatiotemporal Resolution Using the Zebrafish Embryo. Dev. Cell 2019, 48 (4), 554 572.e7. https://doi.org/10.1016/j.devcel.2019.01.014.

(21) Collot, M.; Ashokkumar, P.; Anton, H.; Boutant, E.; Faklaris, O.; Galli, T.; Mély, Y.; Danglot, L.; Klymchenko, A. S. MemBright: A Family of Fluorescent Membrane Probes for Advanced Cellular Imaging and Neuroscience. Cell Chem. Biol. 2019, 26 (4), 600-614.e7. https://doi.org/10.1016/j.chembiol.2019.01.009.

(22) Collot, M.; Boutant, E.; Fam, K. T.; Danglot, L.; Klymchenko, A. S. Molecular Tuning of Styryl Dyes Leads to Versatile and Efficient Plasma Membrane Probes for Cell and Tissue Imaging. Bioconjug. Chem. 2020, 31 (3), 875-883. https://doi.org/10.1021/acs.bioconjchem.0c00023.

(23) Moon, S.; Yan, R.; Kenny, S. J.; Shyu, Y.; Xiang, L.; Li, W.; Xu, K. Spectrally Resolved, Functional Super-Resolution Microscopy Reveals Nanoscale Compositional Heterogeneity in LiveCell Membranes. J. Am. Chem. Soc. 2017, 139 (32), 10944-10947. https://doi.org/10.1021/jacs.7b03846.

(24) Liu, C.; Gao, X.; Yuan, J.; Zhang, R. Advances in the Development of Fluorescence Probes for Cell Plasma Membrane Imaging. TrAC Trends Anal. Chem. 2020, 133, 116092. https://doi.org/10.1016/j.trac.2020.116092.

(25) Klymchenko, A. S. Solvatochromic and Fluorogenic Dyes as Environment-Sensitive Probes: Design and Biological Applications. Acc. Chem. Res. 2017, 50 (2), 366-375. https://doi.org/10.1021/acs.accounts.6b00517.

(26) Owen, D. M.; Rentero, C.; Magenau, A.; Abu-Siniyeh, A.; Gaus, K. Quantitative Imaging of Membrane Lipid Order in Cells and Organisms. Nat. Protoc. 2012, 7 (1), 24-35. https://doi.org/10.1038/nprot.2011.419.

(27) Kucherak, O. A.; Oncul, S.; Darwich, Z.; Yushchenko, D. A.; Arntz, Y.; Didier, P.; Mély, Y.; Klymchenko, A. S. Switchable Nile Red-Based Probe for Cholesterol and Lipid Order at the Outer Leaflet of Biomembranes. J. Am. Chem. Soc. 2010, 132 (13), 4907 4916. https://doi.org/10.1021/ja100351w.

(28) Klymchenko, A. S.; Kreder, R. Fluorescent Probes for Lipid Rafts: From Model Membranes to Living Cells. Chem. Biol. 2014, 21 (1), 97-113. https://doi.org/10.1016/j.chembiol.2013.11.009.

(29) Danylchuk, D. I.; Moon, S.; Xu, K.; Klymchenko, A. S. Switchable Solvatochromic Probes for Live-Cell Super-Resolution
Imaging of Plasma Membrane Organization. Angew. Chem. 2019, 131 (42), 15062-15066. https://doi.org/10.1002/ange.201907690.

(30) Shynkar, V. V.; Klymchenko, A. S.; Kunzelmann, C.; Duportail, G.; Muller, C. D.; Demchenko, A. P.; Freyssinet, J.-M.; Mely, Y. Fluorescent Biomembrane Probe for Ratiometric Detection of Apoptosis. J. Am. Chem. Soc. 2007, 129 (7), 2187-2193. https://doi.org/10.1021/ja068008h.

(31) Ashokkumar, P.; Ashoka, A. H.; Collot, M.; Das, A.; Klymchenko, A. S. A Fluorogenic BODIPY Molecular Rotor as an Apoptosis Marker. Chem. Commun. 2019, 55 (48), 6902-6905. https://doi.org/10.1039/C9CC03242H.

(32) Kuimova, M. K.; Yahioglu, G.; Levitt, J. A.; Suhling, K. Molecular Rotor Measures Viscosity of Live Cells via Fluorescence Lifetime Imaging. J. Am. Chem. Soc. 2008, 130 (21), 6672-6673. https://doi.org/10.1021/ja800570d.

(33) López-Duarte, I.; Vu, T. T.; Izquierdo, M. A.; Bull, J. A.; Kuimova, M. K. A Molecular Rotor for Measuring Viscosity in Plasma Membranes of Live Cells. Chem. Commun. 2014, 50 (40), 5282 5284. https://doi.org/10.1039/C3CC47530A.

(34) Colom, A.; Derivery, E.; Soleimanpour, S.; Tomba, C.; Molin, M. D.; Sakai, N.; González-Gaitán, M.; Matile, S.; Roux, A. A Fluorescent Membrane Tension Probe. Nat. Chem. 2018, 10 (11), 1118-1125. https://doi.org/10.1038/s41557-018-0127-3.

(35) Goujon, A.; Straková, K.; Sakai, N.; Matile, S. Streptavidin Interfacing as a General Strategy to Localize Fluorescent Membrane Tension Probes in Cells. Chem. Sci. 2018, 10 (1), 310-319. https://doi.org/10.1039/C8SC03620A.

(36) Ke, G.; Zhu, Z.; Wang, W.; Zou, Y.; Guan, Z.; Jia, S.; Zhang, H.; Wu, X.; Yang, C. J. A Cell-Surface-Anchored Ratiometric Fluorescent Probe for Extracellular PH Sensing. ACS Appl. Mater Interfaces $\mathbf{2 0 1 4}, \quad 6 \quad$ (17), $15329-15334$. https://doi.org/10.1021/am503818n.

(37) A Cell-Surface-Specific Ratiometric Fluorescent Probe for Extracellular pH Sensing with Solid-State Fluorophore | ACS Sensors https://pubs-acs-org.scd-rproxy.ustrasbg.fr/doi/10.1021/acssensors.8b00514 (accessed 2021 -04 -26).

(38) Peng, P.; Li, H.; Bai, L.; Wang, L.; Chen, B.; Yu, C.; Zhang, C.; Ge, J.; Li, L.; Huang, W. Photocontrollable Fluorogenic Probe for Visualizing Near-Membrane Hypochlorite in Live Cells. ChemistrySelect 2018, 3 (21), 5981-5986. https://doi.org/10.1002/slct.201800777.

(39) Yao, H.-W.; Zhu, X.-Y.; Guo, X.-F.; Wang, H. An Amphiphilic Fluorescent Probe Designed for Extracellular Visualization of Nitric Oxide Released from Living Cells. Anal. Chem. 2016, 88 (18), 9014-9021. https://doi.org/10.1021/acs.analchem.6b01532.

(40) Zhang, X.; Wang, B.; Xiao, Y.; Wang, C.; He, L. Targetable, Two-Photon Fluorescent Probes for Local Nitric Oxide Capture in the Plasma Membranes of Live Cells and Brain Tissues. Analyst 2018, 143 (17), 4180-4188. https://doi.org/10.1039/C8AN00905H.

(41) Niu, L.-Y.; Chen, Y.-Z.; Zheng, H.-R.; Wu, L.-Z.; Tung, C.-H.; Yang, Q.-Z. Design Strategies of Fluorescent Probes for Selective Detection among Biothiols. Chem. Soc. Rev. 2015, 44 (17), 6143-6160. https://doi.org/10.1039/C5CS00152H.

(42) Gao, W.; Li, T.; Wang, J.; Zhao, Y.; Wu, C. ThioetherBonded Fluorescent Probes for Deciphering Thiol-Mediated Exchange Reactions on the Cell Surface. Anal. Chem. 2017, 89 (1), 937944. https://doi.org/10.1021/acs.analchem.6b04096. 
(43) Li, T.; Gao, W.; Liang, J.; Zha, M.; Chen, Y.; Zhao, Y.; Wu, C. Biscysteine-Bearing Peptide Probes To Reveal Extracellular Thiol-Disulfide Exchange Reactions Promoting Cellular Uptake. Anal. Chem. 2017, 89 (16), 8501-8508. https://doi.org/10.1021/acs.analchem.7b02084.

(44) Yuan, L.; Lin, W.; Zheng, K.; Zhu, S. FRET-Based SmallMolecule Fluorescent Probes: Rational Design and Bioimaging Applications. Acc. Chem. Res. 2013, 46 (7), 1462-1473. https://doi.org/10.1021/ar300273v.

(45) Rowland, C. E.; Brown, C. W.; Medintz, I. L.; Delehanty, J. B. Intracellular FRET-Based Probes: A Review. Methods Appl. Fluoresc. 2015, 3 (4), 042006. https://doi.org/10.1088/2050$6120 / 3 / 4 / 042006$

(46) Wu, L.; Huang, C.; Emery, B. P.; Sedgwick, A. C.; Bull, S. D.; He, X.-P.; Tian, H.; Yoon, J.; Sessler, J. L.; James, T. D. Förster Resonance Energy Transfer (FRET)-Based Small-Molecule Sensors and Imaging Agents. Chem. Soc. Rev. 2020, 49 (15), 5110-5139. https://doi.org/10.1039/C9CS00318E

(47) Zhang, W.; Huo, F.; Cheng, F.; Yin, C. Employing an ICTFRET Integration Platform for the Real-Time Tracking of SO2 Metabolism in Cancer Cells and Tumor Models. J. Am. Chem. Soc. 2020, 142 (13), 6324-6331. https://doi.org/10.1021/jacs.0c00992.

(48) Wen, Y.; Huo, F.; Wang, J.; Yin, C. Multicolor Fluorescence Based on FRET Regulated by Functional Peptides To Screen High Metastatic Potential Cancer Cells. Anal. Chem. 2019, 91 (23), 15057-15063. https://doi.org/10.1021/acs.analchem.9b03731.

(49) Hope, M. J.; Bally, M. B.; Webb, G.; Cullis, P. R. Production of Large Unilamellar Vesicles by a Rapid Extrusion Procedure. Characterization of Size Distribution, Trapped Volume and Ability to Maintain a Membrane Potential. Biochim. Biophys. Acta BBA Biomembr. 1985, 812 (1), 55-65. https://doi.org/10.1016/00052736(85)90521-8.
(50) Lautscham, L. A.; Lin, C. Y.; Auernheimer, V.; Naumann, C. A.; Goldmann, W. H.; Fabry, B. Biomembrane-Mimicking Lipid Bilayer System as a Mechanically Tunable Cell Substrate. Biomaterials 2014, $35 \quad$ (10), $\quad 3198-3207$. https://doi.org/10.1016/j.biomaterials.2013.12.091.

(51) de la Haba, C.; Palacio, J. R.; Martínez, P.; Morros, A. Effect of Oxidative Stress on Plasma Membrane Fluidity of THP-1 Induced Macrophages. Biochim. Biophys. Acta BBA - Biomembr. 2013, $1828 \quad$ (2), 357-364. https://doi.org/10.1016/j.bbamem.2012.08.013.

(52) Ashoka, A. H.; Ashokkumar, P.; Kovtun, Y. P.; Klymchenko, A. S. Solvatochromic Near-Infrared Probe for Polarity Mapping of Biomembranes and Lipid Droplets in Cells under Stress. J. Phys. Chem. Lett. 2019, 10 (10), 2414-2421. https://doi.org/10.1021/acs.jpclett.9b00668.

(53) Yang, J.; Chen, H.; Vlahov, I. R.; Cheng, J.-X.; Low, P. S. Evaluation of Disulfide Reduction during Receptor-Mediated Endocytosis by Using FRET Imaging. Proc. Natl. Acad. Sci. 2006, 103 (37), 13872-13877. https://doi.org/10.1073/pnas.0601455103.

(54) Lee, M. H.; Yang, Z.; Lim, C. W.; Lee, Y. H.; Dongbang, S.; Kang, C.; Kim, J. S. Disulfide-Cleavage-Triggered Chemosensors and Their Biological Applications. Chem. Rev. 2013, 113 (7), 50715109. https://doi.org/10.1021/cr300358b.

(55) Collot, M.; Kreder, R.; Tatarets, A. L.; Patsenker, L. D.; Mely, Y.; Klymchenko, A. S. Bright Fluorogenic Squaraines with Tuned Cell Entry for Selective Imaging of Plasma Membrane vs. Endoplasmic Reticulum. Chem. Commun. 2015, 51 (96), 1713617139. https://doi.org/10.1039/C5CC06094J.

(56) Ballatori, N.; Krance, S. M.; Notenboom, S.; Shi, S.; Tieu, K.; Hammond, C. L. Glutathione Dysregulation and the Etiology and Progression of Human Diseases. 2009, 390 (3), 191-214. https://doi.org/10.1515/BC.2009.033. 